\title{
ROLE OF APOLIPOPROTEIN E AND ESTROGEN IN MOSSY FIBER SPROUTING IN HIPPOCAMPAL SLICE CULTURES
}

\author{
B. TETER,* M. E. HARRIS-WHITE, S. A. FRAUTSCHY and G. M. COLE \\ Greater Los Angeles Veteran's Healthcare System, Sepulveda, and Departments of Medicine and Neurology, \\ University of California, Los Angeles, 16111 Plummer Street, Sepulveda CA 91343, U.S.A.
}

\begin{abstract}
A role for apolipoprotein E is implicated in regeneration of synaptic circuitry after neural injury. The in vitro mouse organotypic hippocampal slice culture system shows Timm's stained mossy fiber sprouting into the dentate gyrus molecular layer in response to deafferentation of the entorhinal cortex. We show that cultures derived from apolipoprotein E knockout mice are defective in this sprouting response; specifically, they show no sprouting in the dorsal region of the dentate gyrus, yet retain sprouting in the ventral region. Dorsal but not ventral sprouting in cultures from $\mathrm{C} 57 \mathrm{Bl} / 6 \mathrm{~J}$ mice is increased $75 \%$ by treatment with $100 \mathrm{pM} 17 \beta$-estradiol; this response is blocked by both progesterone and tamoxifen.

These results show that neuronal sprouting is increased by estrogen in the same region where sprouting is dependent on apolipoprotein E. Sprouting may be stimulated by estrogen through its up-regulation of apolipoprotein $\mathrm{E}$ expression leading to increased recycling of membrane lipids for use by sprouting neurons. Estrogen and apolipoprotein E may therefore interact in their modulation of both Alzheimer's disease risk and recovery from CNS injury.
\end{abstract}

Key words: apolipoprotein E, estrogen, neurite sprouting, Alzheimer's disease.

The adult central and peripheral nervous systems (CNS and PNS) respond to injury with limited yet effective regeneration of synaptic circuitry which re-establishes lost function. Although little is known about the mechanism of recovery, accumulating evidence implicates a role for apolipoprotein $\mathrm{E}$ (ApoE), possibly through its function in membrane lipid recycling. ${ }^{52,53}$ ApoE expression increases in reactive responses of both astrocytes and microglia which, in turn, play critical roles in CNS response to and recovery from injury. ${ }^{10}$ ApoE in the brain represents an endogenous pool synthesized by glia. Although this has been attributed primarily to astrocytes, ${ }^{51,78}$ we and others have shown that microglia express ApoE..$^{47,71,75}$

ApoE genotype is a major risk factor for Alzheimer's disease (AD) where isotype E4 increases risk and accelerates age of onset (reviewed in Roses and Saunders ${ }^{58}$ ). In AD there is extensive loss of entorhinal cortex (EC) neurons, ${ }^{28}$ loss of

*To whom correspondence should be addressed.

Abbreviations: AD, Alzheimer's disease; ApoE, apolipoprotein $\mathrm{E}$ (gene and protein); ApoE-KO, (also, EKO) ApoE "knockout" mouse, targeted-mutation transgenic eliminating ApoE expression; BSA, bovine serum albumin; C57, C57Bl/6J mouse strain; DG, dentate gyrus (of the hippocampus); DIV, days in vitro; EC, entorhinal cortex; ECL, EC lesion; HEPES, $N$-2-hydroxyethylpiperazine- $N$-2-ethanesulfonic acid; IML, inner molecular layer (of the dentate gyrus); IR, immunoreactivity; LDLR, low density lipoprotein; ML, molecular layer; OHSC, organotypic hippocampal slice culture; OML, outer molecular layer (of the dentate gyrus); PD, postnatal day; PNS, peripheral nervous system; RT, room temperature; TBS, Tris-buffered saline. synaptophysin immunoreactivity in the hippocampus, ${ }^{26,60}$ and neuronal cytoskeletal disruption. ${ }^{42}$ A subset of patients with unknown ApoE genotype have shown regenerative sprouting in the dentate gyrus (DG). ${ }^{23}$

Studies of the ApoE knockout (ApoE-KO) mouse ${ }^{50}$ have revealed insight into ApoE's functions, both peripherally and centrally. ApoE knockout mice, although neuropathologically normal, show numerous CNS defects including impaired memory and learning deficits, some of which are age-dependent. ${ }^{24,31,40,41,77}$ They also show cholinergic changes ${ }^{24}$ and age-related disruption in the dendritic cytoskeleton and reduced synaptophysin and microtubule-associated protein-2 immunoreactivity in the hippocampus ${ }^{37}$ (reviewed in Ref. 40). ApoE-KO mice also show defects in responses to injury, including cerebral ischemia, ${ }^{13,32}$ and impaired synaptic regeneration (recovery of synaptophysin-IR) in the outer molecular layer (OML) after EC lesion (ECL) ${ }^{38}$ However, some of these effects are not consistently observed. ${ }^{1 \mathrm{a}, 22,40}$ In addition to manipulating ApoE by gene knockout, functional effects of elevating ApoE levels in brain and CNS cells in vitro have been shown by estrogen ${ }^{68,71}$ and by ventricular infusion of human ApoE into the ApoE-KO mouse correcting the cognitive and neuron structure defects. ${ }^{41}$

The hippocampus is a model system for synaptic plasticity and re-organization after injury because of its roles in learning and memory as well as its status as a locus for many acute and degenerative conditions. ${ }^{61}$ Mechanisms of axonal sprouting in response 
to neural deafferentation have been investigated in an in vitro mouse organotypic hippocampal slice culture (OHSC) system. This system mimics many in vivo events and therefore provides a powerful system to identify relevant mechanisms. OHSC continues to develop and retains organotypic features of the intact hippocampus, ${ }^{2,6,72}$ including development of the mossy fiber pathway that arises from dentate granule cells and projects to the CA3 pyramidal cells, ${ }^{74,81}$ as well as other synaptic development phenomena that parallel those observed in vivo. ${ }^{21,45}$

The preparation of hippocampal slices transects the perforant path, thereby removing the major extrinsic innervation by the EC to the granule cell dendritic field in the OML, as well as the commissural projection to the inner molecular layer (IML). ${ }^{19}$ This deafferentation stimulates sprouting of granule cell mossy axon collaterals into the molecular layer (ML), where they are not normally found in abundance. ${ }^{20,63,81}$ There they make aberrant synapses with dendrites of the deafferented granule cells ("reactive synaptogenesis") that are electrophysiologically functional. ${ }^{21,72}$

\section{EXPERIMENTAL PROCEDURES}

\section{Animals}

C56B1/6J and C56B1/6J-ApoEtm1Unc (ApoE-knockout) mice were obtained from Jackson Labs and maintained as an inbred colony. The ApoE-knockout mice were the 10th generation backcross to $\mathrm{C} 56 \mathrm{Bl} / 6 \mathrm{~J}$ by Jackson Labs. To minimize animal suffering, all surgical and animal care procedures were carried out with strict adherence to the guidlines set out in the NIH guide for the care and use of laboratory animal, NIH Publication no. 80-23. Mice were kept on a $12 \mathrm{~h}$ light-dark cycle and provided food and water ad libitum.

\section{Organotypic hippocampal slice culture}

Postnatal day (PD) 7 pups were anesthetized with $\mathrm{CO}_{2}$, sterilized and decapitated. Hippocampal slice cultures were prepared according to the method of Stoppini et al. ${ }^{73}$ with some modifications. ${ }^{25}$ Hippocampi from PD7 pups were sliced to $400 \mu \mathrm{m}$ on a Stoelting tissue chopper and arranged in anatomical order (septal to temporal) in a $24 \mathrm{~mm}$ diameter $0.4 \mu \mathrm{m}$-pore clear membrane insert (Costar) in a six-well tissue culture tray containing $1.2 \mathrm{ml}$ media. The medium was changed every two days for the five days in vitro (DIV), then every three days. Slice culture medium consisted of $64 \%$ minimal essential medium + HEPES without Phenol Red (Gibco), 32\% Hanks' balanced salt solution without Phenol Red (Sigma), $6.5 \mathrm{mg} / \mathrm{ml}$ glucose, penicillin-streptomycin $(50 \mathrm{U} / \mathrm{ml}-0.05 \mathrm{mg} / \mathrm{ml})$, and the serum substitute $\mathrm{TCM}^{\mathrm{TM}}$ (final concentration $2 \%$; ICN Biomedicals) which provides $675 \mu \mathrm{g} / \mathrm{ml}$ total protein (final concentration) consisting of a proprietary mixture of bovine serum albumin (BSA)(heat-treated and fatty acidfree), transferrin, and insulin (the latter two have been shown to be necessary and sufficient for neuron growth and survival in vitro ${ }^{1}$ ).

The degree of mossy fiber sprouting is dependent on the position of the slice in the septal-temporal axis of the hippocampus; sprouting is greatest in septal slices, is slightly reduced in medial slices, and is greatly reduced in temporal slices. ${ }^{8,12}$ For this reason, the positional identity of slices was maintained during hippocampal dissection and placement on the culture insert membrane. Quantitative analysis of sprouting confirmed this septal-temporal gradient of sprouting (data not shown). Because of this gradient, the number of septal, medial, and temporal slices analysed was the same for each treatment group; the number of surviving slices per treatment group was $14 \pm 1$ for all experiments.

\section{Culture medium and hormone treatment}

$17 \beta$-Estradiol, progesterone and tamoxifen citrate (Sigma) were dissolved in ethanol, ethanol, and water, respectively, to a concentration of $10^{-3} \mathrm{M}$, and then diluted into culture media to final concentrations of $10^{-10} \mathrm{M}$, $10^{-7} \mathrm{M}$, and $10^{-7} \mathrm{M}$, respectively. Control cultures received an equivalant amount of ethanol ( $0.1 \%$ final concentration). Hormone treatment began at one DIV.

\section{Timms's heavy metal staining}

The Timm's stain procedure was adapted for slice cultures by Zimmer and Gahwiler. ${ }^{81}$ Briefly, cultures are treated with $1 \% \mathrm{Na}_{2} \mathrm{~S}$ for $10 \mathrm{~min}$, fixed in $70 \%$ ethanol, rehydrated, then developed with a solution of gum arabic, citrate buffer, and $\mathrm{AgNO}_{3}$ for $35-40 \mathrm{~min}$ at $26^{\circ}$, followed by washing in cold water. The membrane was cut out of the plastic insert, mounted on gelatin-coated slides, dehydrated in ethanol, followed by clearing in xylene and mounting in Permount. Histological preparations were analysed by quantitation of the Timm's staining.

\section{Quantitation of mossy fiber sprouting}

Slices were visualized on an Olympus VanoxT at $\times 40$ magnification and digitized images were captured with an Optronix LX450 video camera using NIH Image version 1.60 software, a public domain software (available at http://www.rsb.info.nih.gov/nihimage/). Gain and offset parameters were set so that no pixels were saturated at either end of the gray-level spectrum, and maintained constant for each experiment's analysis. Mossy fiber sprouting was measured as described by Coltman et al. ${ }^{12}$ with treatment group blind to the operator. Using NIH Image, the Timm's staining was quantitated in two supra-granular regions, ventral and dorsal (dorsal included the apical region). Optical density was measured in a $100 \mu \mathrm{m}$ by $50 \mu \mathrm{m}$ box placed over the three most intensely staining areas within each of the dorsal, ventral, and central hilar regions. The average transmittance within these regions was converted to gray levels by NIH Image such that $100 \%$ transmittance $=0$ and $0 \%$ transmittance $=255$. Background transmittance measurements taken in the adjacent hippocampal fissure were subtracted from measurements of the two supragranular regions. These corrected sprouting region measurements were divided by the hilus measurement which gives the sprouting index; this normalization to the hilus eliminates variability due to Timm's staining differences between cultures and between experiments. ${ }^{12}$ The sprouting indices were analysed by ANOVA with Fisher PLD post hoc test to assess the significance of differences between groups.

\section{Apolipoprotein E immunoreactivity}

After 18 DIV, slices were submersion-fixed in $4 \%$ paraformaldehyde for $1 \mathrm{~h}$ followed by three rinses in Trisbuffered saline (TBS). Slices were either whole-mounted onto poly-L-lysine-coated slides or $12 \mu \mathrm{m}$ sections were cut on a Zeiss cryostat. Endogenous peroxidase activity was suppressed with $0.5 \% \mathrm{H}_{2} \mathrm{O}_{2}$ in methanol for $15 \mathrm{~min}$ at room temperature (RT) and non-specific binding sites blocked with $5 \%$ normal goat serum in 3\% BSA for $1 \mathrm{~h}$ at RT. The ApoE antibody was applied (overnight at $4^{\circ} \mathrm{C}$ ) 
a

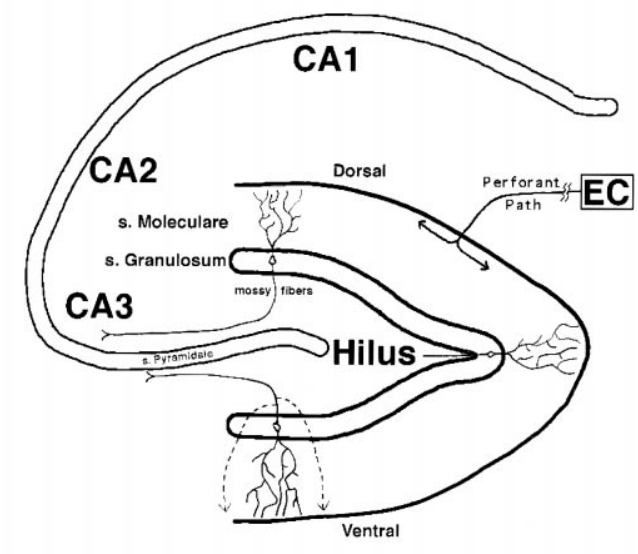

C

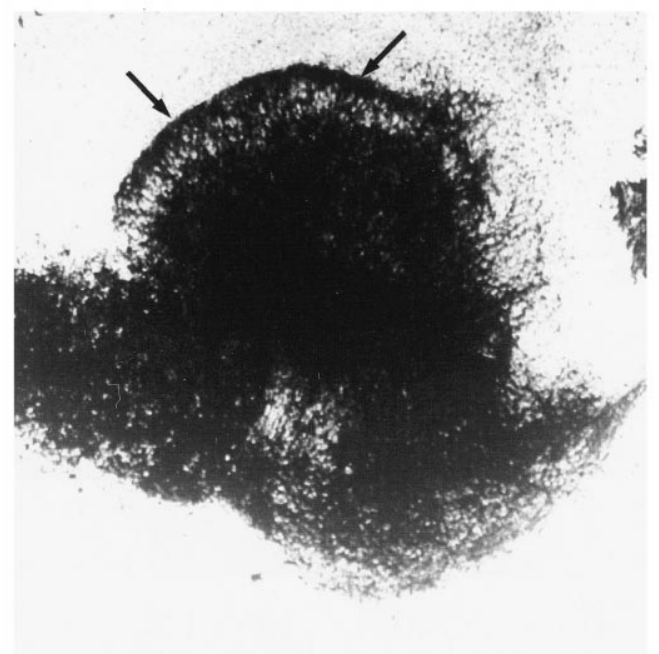

b

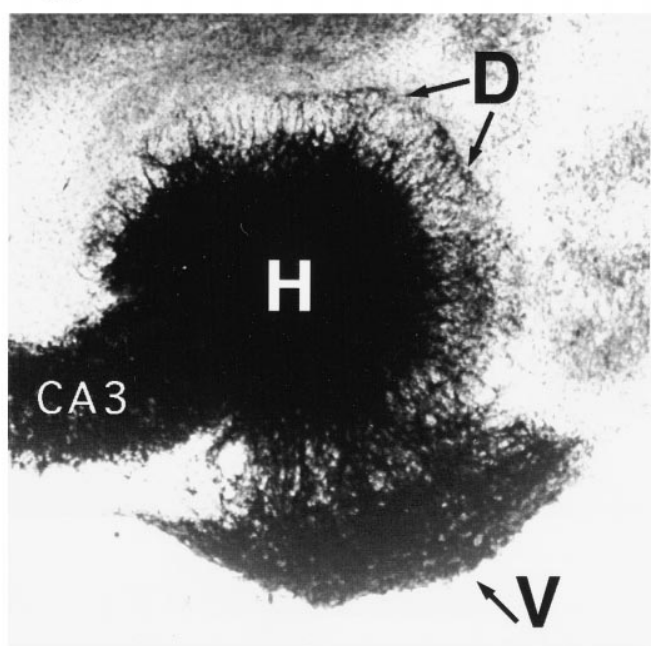

d

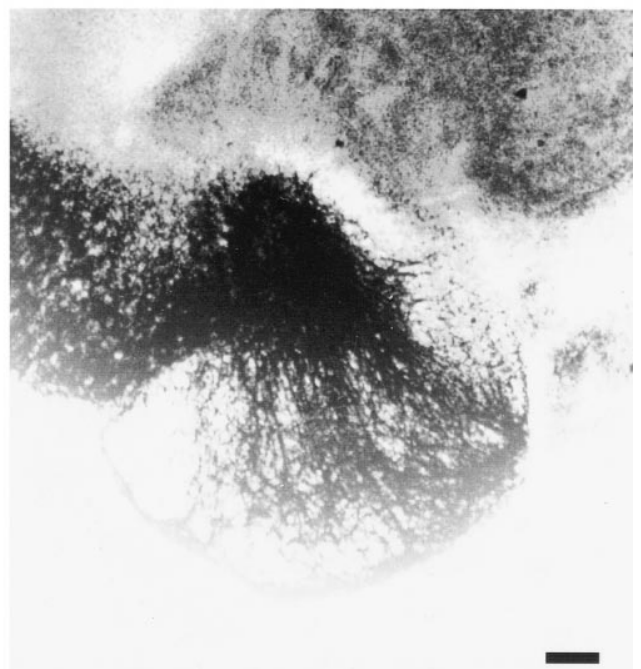

Fig. 1. Mossy fiber sprouting in hippocampal slice cultures. (a) Diagram of hippocampus showing granule cell dendritic tree in the molecular layer with its innervation from the perforant path of the entorhinal cortex (EC), the mossy fibers from the hilus projecting through CA3 to the left, and representations of sprouting mossy fibers indicated by dashed lines in the ventral region. Timm's-stained OHSC after 18 DIV (with CA3 projecting to the left) derived from C57B1/6J (b); C57B1/6J treated with $17 \beta$-estradiol $\left(10^{-10} \mathrm{M}\right)(\mathrm{c})$; or ApoE-KO (d). H, hilus; D, dorsal sprouting region; $\mathrm{V}$, ventral sprouting region. Scale $\mathrm{bar}=100 \mu \mathrm{m}$.

to slices at a 1:800 dilution in TBS containing $0.1 \%$ Tween-20, 3\% BSA and $8 \mathrm{mM}$ sodium azide. Slices were then rinsed and incubated with a biotinylated anti-mouse secondary antibody (1:500 in TBS plus Tween-20; $1 \mathrm{~h}$ at RT). Slices were rinsed and incubated with avidin-biotinperoxidase complex solution (Elite ABC kit, Vector Labs) for $45 \mathrm{~min}$ at RT. Diaminobenzidine-metal enhanced chromagen (Pierce) was used to reveal ApoE antibody binding.

\section{RESULTS}

Mossy fiber sprouting in wild-type mice organotypic hippocampal slice culture

Timm's stained mossy fibers showed typical supragranular sprouting after 18 DIV. Sprouting fibers originating from the hilar region projected through the granule cell layer to the molecular layer in the dorsal, apical, and ventral regions (Fig. $1 \mathrm{a}, \mathrm{b})$. It is notable that the Timm's stained fiber sprouting in the ventral blade of the dentate was more extensive, projecting throughout the whole molecular layer. Sprouting was quantitated by normalization to Timm's staining in the hilar region. ${ }^{12}$ The resulting sprouting index was significantly higher in the ventral region than in the dorsal (Table 1); however, ventral sprouting levels were less than the highest levels reported, which reached $0.9{ }^{12}$ 
Table 1. Quantitative analysis of Timm's-stained mossy fiber sprouting

\begin{tabular}{lllllll}
\hline Strain, treatment & \multicolumn{2}{c}{ Dorsal } & & \multicolumn{2}{c}{ Ventral } \\
\cline { 2 - 3 } & mean & S.D. & mean & S.D. \\
& & & & & \\
\hline C57BL6/J & 0.35 & 0.04 & & 0.60 & 0.08 \\
Control & $0.68^{*}$ & 0.06 & & 0.66 & 0.04 \\
Estradiol & $0.40^{* *}$ & 0.08 & & n.d. & n.d. \\
Estradiol + progesterone & 0.44 & 0.09 & & n.d. & n.d. \\
Progesterone & $0.40^{* *}$ & 0.15 & & n.d. & n.d. \\
Estradiol + tamoxifen & 0.35 & 0.06 & & n.d. & n.d. \\
Tamoxifen & & & & \\
ApoE-KO & $<0.01$ & & & 0.54 & 0.06 \\
Control & $<0.01$ & & & 0.50 & 0.08 \\
Estradiol $\left(10^{-10} \mathrm{M}\right)$ & & & & & \\
\hline
\end{tabular}

Fourteen slices per treatment group were analysed; control, $0.1 \%$ ethanol; estradiol, $10^{-10} \mathrm{M}$; progesterone, $10^{-7} \mathrm{M}$; tamoxifen, $10^{-7} \mathrm{M}$.

${ }^{*} P<0.01$ compared to control; ${ }^{* *} P<0.05$ compared to estradiol alone; n.d., not determined.

\section{Effect of lack of mouse apolipoprotein E expression on mossy fiber sprouting}

In contrast to hippocampal slice cultures derived from the background strain, C56Bl/6J (Fig. 1b), cultures derived from ApoE-KO mice did not show Timm's-stained sprouting of mossy fibers into the supragranular region of the dorsal molecular layer (Fig. 1d), even in cultures maintained to 28 DIV (data not shown). The pattern of sprouting in ApoE-KO was limited to the ventral region $(\mathrm{V}$, in Fig. 1b). This pattern was observed in over 250 slices from at least 20 animals from four litters of ApoE-KO. Quantitative analysis showed no difference in the degree of ventral sprouting in ApoE-KO compared to $\mathrm{C} 57 \mathrm{~B} 1 / 6 \mathrm{~J}$ (Table 1). These results show that sprouting in the dorsal region was ApoE-dependent while that in the ventral region was ApoE-independent.

\section{Effect of hormones on mossy fiber sprouting}

$17 \beta$-Estradiol treatment $(100 \mathrm{pM})$ increased sprouting in the dorsal region (Fig. 1c, arrows). Quantitative analysis showed that sprouting was significantly increased by $75 \%$ (Table 1 ). Progesterone $(100 \mathrm{nM})$ had no effect by itself, but blocked the $17 \beta$-estradiol stimulation (Table 1). The $17 \beta-$ estradiol antagonist, tamoxifen, also blocked the $17 \beta$-estradiol stimulation (Table 1). The ventral region sprouting was not affected by $17 \beta$-estradiol in either $\mathrm{C} 57 \mathrm{Bl} / 6 \mathrm{~J}$ or ApoE-KO (Table 1). The lack of sprouting in the dorsal region of ApoE-KO was not restored by $17 \beta$-estradiol treatment (Table 1 ).

\section{Apolipoprotein E immunoreactivity in hippocampal slice cultures}

The pattern of ApoE immunoreactivity in hippopcampal slice cultures was determined after 18 DIV.
ApoE immunoreactivity was found fairly uniformly distributed throughout the hippocampal regions; staining was slightly higher in the stratum oriens and stratum radiatum regions around CA1 (Fig. 2) extending through the stratum pyramidale in CA3 and dentate gyrus, and slightly lower in the stratum moleculare. The majority of immunoreactive cells appeared to be astrocytes (Fig. 2, inset arrows).

\section{DISCUSSION}

Although ApoE deficiency does not compromise PNS regeneration, perhaps by compensatory overproduction of another apolipoprotein, ${ }^{55}$ it appears to be essential in the CNS. ${ }^{37,38,52}$ Results shown here indicate that ApoE is required for sprouting of mossy fibers to the OML in the dorsal DG in response to EC deafferentation in OHSC. This is consistent with the impaired synaptic regeneration in ApoE-KO in response to entorhinal cortex deafferentation in vivo. ${ }^{38}$

ApoE has many activities which could account for its CNS effects, with cholesterol and phospholipid metabolism ${ }^{36}$ consistently implicated in its role in CNS and PNS plasticity after injury..$^{5,33} \mathrm{~A}$ model for this role has been described ${ }^{5,52,53,59}$ where glia phagocytosing degenerating terminals esterify cholesterol from scavenged membrane lipid, repackaged it with ApoE and secrete it, facilitating delivery of cholesterol to neurons via their ApoE receptors for neurite growth. In support of this model, (i) ApoE synthesis increases in the deafferented ML after ECL ${ }^{53,54}$ possibly due to up-regulation by intracellular free cholesterol and oxidized low-density lipoprotein (LDL); ${ }^{7,66,67}$ (ii) ApoE-KO fails to clear degenerating terminals in the ML after ECL, ${ }^{17}$ an activity attributed to both astrocytes and microglia; ${ }^{3}$ (iii) ApoE-KO and LDL receptor-knockout mice show altered synaptic plasma membrane cholesterol distribution and phospholipid content, ${ }^{29}$ a phenomenon also observed in aged wild-type mice; ${ }^{30}$ and (iv) ApoE stimulates neurite outgrowth. ${ }^{16,48,56,73 a}$

The regional restriction of the defective sprouting response may reflect the differences in developmental age between dorsal and ventral DG. Granule cell mossy fibers in the dorsal DG develop earlier (beginning at PD3) than in the ventral region, ${ }^{35,65}$ and the granule cell terminal field in the ML as well as its entorhinal innervation develop earlier in the dorsal DG. ${ }^{18,34,65}$ Developmental age of granule cells and their mossy projections may explain differential mossy fiber sprouting observed in the hippocampus septal-temporal axis. ${ }^{12,34,57,69}$ Since $85 \%$ of granule cells are born postnatally and the mossy fiber system develops unusually slowly over the first three weeks postnatally, ${ }^{20,65}$ the large increase in ApoE expression at this time ${ }^{15,44,46}$ could play an important role in determining the consequences of neurodegeneration. Our results showing that mossy fiber sprouting 


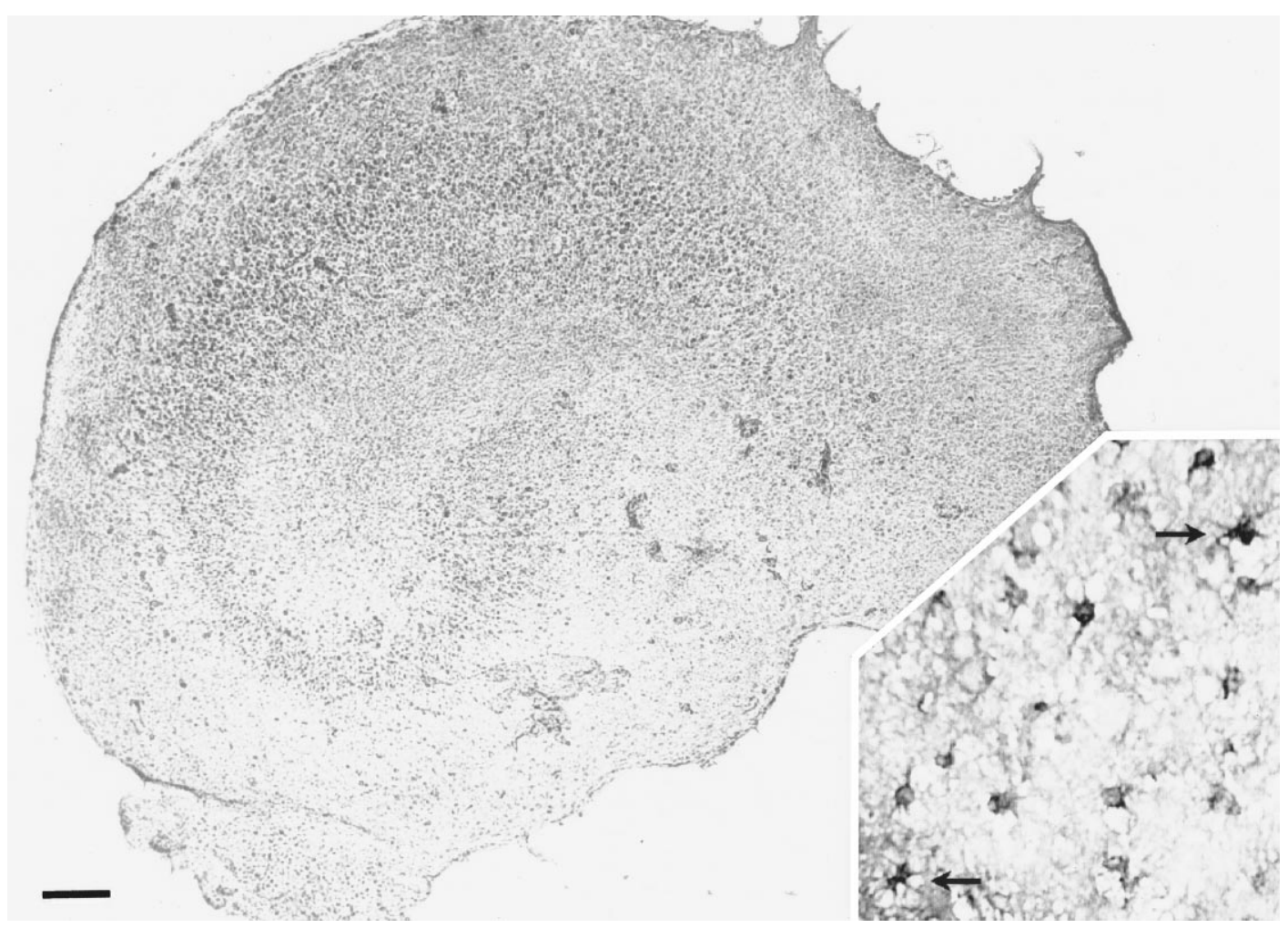

Fig. 2. ApoE immunoreactivity in hippocampal slice culture. ApoE immunoreactivity of a whole mount of a hippocampal slice at 18 DIV shows overall diffuse staining. At higher power, immunoreactivity of a $12 \mu \mathrm{m}$ section of a hippocampal slice in the stratum pyramidale layer in CA1 shows cellular staining with astrocytic morphology (inset; arrows). Scale bar $=200 \mu \mathrm{M}$.

in the older, dorsal DG is ApoE-dependent, while sprouting in the younger, ventral DG in ApoE-independent, may reflect changes in hippocampal plasticity during development that represent a developmental age-dependent change in the capability of the granule cells to respond to deafferentation or an age-dependent change in the underlying mechanism of sprouting.

Sprouting shows an age-dependent reduction in response to $\mathrm{ECL}^{62}$ which models aspects of EC neurodegeneration in $\mathrm{AD} .^{23}$ Aged humans show increased intra- and supra-granular Timm's staining, suggesting that the ML might be partially deafferented with age. ${ }^{9}$ Although some AD patients have shown aspects of regenerative sprouting in the $\mathrm{DG},{ }^{23}$ whether compensatory growth is widespread and whether it reverses cognitive deficits has been debated, since functional recovery requires that reactive synaptogenesis not exacerbate circuitry dysfunction. . $^{14,39,52}$

AD prevalence is increased in women, and postmenopausal estrogen replacement therapy reduces $\mathrm{AD}$ risk ${ }^{27,49}$ delays onset, ${ }^{74 \mathrm{a}}$ and improves cognition in both $\mathrm{AD}$ and non-AD. ${ }^{64}$ Among estrogen's numerous CNS effects, neural-organizational effects include enhanced neurite sprouting, which has been shown for several brain regions in in vivo, organotypic, and in vitro systems. ${ }^{26,43,76}$ Our results of estrogen stimulating sprouting of mossy fibers in
OHSC extend these studies to sprouting that has a functional compensatory effect in a neuronal population pathologically relevant to $\mathrm{AD}$.

Estrogen effects can be either receptor- or nonreceptor-mediated. Estrogen-induced sprouting in OHSC is probably receptor-mediated since the estrogen receptor antagonist, tamoxifen, which has been shown to block estrogen-induced neuritogenesis in hypothalamic neurons, ${ }^{11}$ blocked estrogen's effect. In addition, progesterone also blocked estrogen-induced sprouting, consistent with previous reports in which progesterone blocks estrogen's induction of hippocampal dendritic spine density. ${ }^{80}$

It is not known whether these effects are due to direct action of estrogen on neurons, which could occur at several levels: activational, ${ }^{79}$ trophic, ${ }^{4,11,76}$ and protective (including anti-oxidant and anti-inflammatory). ${ }^{11}$ Alternatively, indirect effects include those on glia. Estrogen upregulation of ApoE synthesis in glia ${ }^{71,75}$ and stimulation of sprouting in OHSC is consistent with the model of glia repackaging cholesterol with ApoE to support new neuronal membrane synthesis (as described above). In addition, our results in OHSC are supported by recent studies in vivo where compensatory synaptogenesis (synaptophysin immunoreactivity) in the hippocampus in response to EC lesion is both stimulated by estrogen 
replacement in ovariectomized animals and is defective in ApoE-KO animals. ${ }^{70}$ The role of ApoE in estrogen-stimulated sprouting in OHSC is supported by the regional coincidence of their effects: (i) sprouting in the dorsal DG was both ApoE-dependent and stimulated by estrogen; (ii) ApoE-independent sprouting in the ventral DG was not affected by estrogen; and (iii) estrogen did not restore sprouting in the dorsal DG of ApoE-KO, suggesting that ApoE expression is required for estrogen's effect on sprouting (see note added in proof). It was recently shown that up-regulation of ApoE synthesis in glia (primarily astrocytes) occurs in CNS regions that undergo estrus cycle-dependent synaptic remodeling. ${ }^{71}$

\section{CONCLUSION}

Together, these results indicate an important interaction between estrogen and ApoE in synaptic plasticity. Although it is not known whether estrogen stimulation of sprouting is relevant to $\mathrm{AD}$, its regulation of ApoE expression in glial cells may, in part, contribute to enhancing compensatory sprouting leading to cognitive improvement.

Acknowledgements - This work was supported by awards from the UCLA Alzheimer's Disease Center, the UCLA Center on Aging, and the UCLA Claude Pepper Older American's Independence Center funded by the NIA (AG10415) to B.T.; VA MERITS to G.M.C. and S.A.F. and UCLA Alzheimer's Disease Center to M.E.H-W.

\section{REFERENCES}

1. Aizenman Y. and De Vellis J. (1987) Brain neurons develop in a serum and glial free environment: effects of transferrin, insulin, insulin-like growth factor I and thyroid hormone on neuronal survival, growth and differentiation. Brain Res. 406, $32-42$.

1a. Anderson R. and Higgins G. A. (1997) Absence of central cholinergic deficits in ApoE knockout mice. Psychopharmacology 132, 135-144.

2. Bahr B. A. (1995) Long-term hippocampal slices: a model system for investigating synaptic mechanisms and pathologic processes. J. Neurosci. Res. 42, 294-305.

3. Bechmann I. and Nitsch R. (1997) Astrocytes and microglial cells incorporate degenerating fibers following entorhinal lesion: a light, confocal, and electron microscopical study using a phagocytosis-dependent labeling technique. Glia 20, 145154.

4. Blanco G., Diaz H., Carrer H. F. and Beauge L. (1990) Differentiation of rat hippocampal neurons induced by estrogen in vitro: effects on neuritogenesis and NaK-ATPase activity. J. Neurosci. Res. 27, 47-54.

5. Boyles J. K., Zoellner C. D., Anderson L. J., Kosik L. M., Pitas R. E., Weisgraber K. H., Hui D. Y., Mahley R. W., GebickeHaerter P. J. and Ignatius M. J. (1989) A role for apolipoprotein E, apolipoprotein A-1, and low density lipoprotein receptors in cholesterol transport during regeneration and remyelination of the rat sciatic nerve. J. clin. Invest. 83, $1015-1031$.

6. Bruce A. J., Sakhi S., Schreiber S. S. and Baudry M. (1995) Development of kainic acid and $N$-methyl-D-aspartic acid toxicity in organotypic hippocampal cultures. Expl Neurol. 132, 209-219.

7. Cader A. A., Steinberg F. M., Mazzone T. and Chait A. (1997) Mechanisms of enhanced macrophage ApoE secretion by oxidized LDL. Lipid Res. 38, 981-991.

8. Casaccia-Bonnefil P., Stelzer A., Federoff H. J. and Bergold P. J. (1995) A role of mossy fiber activation in the loss of CA3 and hilar neurons induced by transduction of the GluR6 kainate receptor subunit. Neurosci. Lett. 191, 67-70.

9. Cassell M. D. and Brown M. W. (1984) Distribution of Timm's stain in the nonsulphide-perfused human hippocampal formation. J. comp. Neurol. 222, 461-471.

10. Chao C. C., Hu S. and Peterson P. K. (1996) Glia: the not so innocent bystanders. J. Neurovirol. 2, $234-239$.

11. Chawen J. A., Torres-Aleman I. and Garcia-Segura L. M. (1992) Trophic effects of estradiol on fetal rat hypothalamic neurons. Neuroendocrinology 56, 895-901.

12. Coltman B. W., Earley E. M., Shahar A., Dudek F. E. and Ide C. F. (1995) Factors influencing mossy fibers collateral sprouting in organotypic slice cultures of neonatal mouse hippocampus. J. comp. Neurol. 362, $209-222$.

13. Connolly E. S., Winfree C. J., Stern D. M., Solomon R. A. and Pinsky D. J. (1996) Exacerbation of stroke outcome in apolipoprotein E null mice; role of abnormal lipid metabolism in the pathogenesis of tissue injury following cerebral ischemia. Stroke 27, 174A.

14. Cotman C. W., Cummings B. J. and Whitson J. S. (1991) The role of misdirected plasticity in plaque biogenesis and Alzheimer's disease pathology. In Growth Factors and Alzheimer's Disease (eds Hefti F., Brachet B. and Christen W. Y.), pp. 222-233. Springer-Verlag, Berlin.

15. Elshourbagy N. A., Liao W. S., Mahley R. W. and Taylor J. M. (1998) Apolipoprotein E mRNA is abundant in the brain and adrenals, as well as in the liver, and is present in other peripheral tissues of rats and marmosets. Proc. natn. Acad. Sci. U.S.A. 82, 203-207.

16. Fagan A. M., Bu G., Sun Y., Daugherty A. and Holtzman D. M. (1996) Apolipoprotein E-containing high density lipoprotein promotes neurite outgrowth and is a ligand for the low density lipoprotein receptor-related protein. J. biol. Chem. 271, $30,121-30,125$.

17. Fagan A. M., Murphy B. A., Patel S. N., Kilbridge J. F., Mobley W. C., Bu G. and Holtzman D. M. (1998) Evidence for normal aging of the septo-hippocampal cholinergic system in apoE $(-/-)$ mice but impaired clearance of axonal degeneration products following injury. Expl Neurol. 151, 314-325.

18. Fricke R. and Cowan W. M. (1977) An autoradiographic study of the development of the entorhinal and commissural afferents to the dentate gyrus of the rat. J. comp. Neurol. 173, 231-250.

19. Frotscher M. (1992) Application of the Golgi/electron microscopy technique for cell identification in immunocytochemical, retrograde labeling, and developmental studies of hippocampal neurons. Microsc. Res. Tech. 23, 306-323.

20. Gaarskjaer F. B. (1986) The organization and development of the hippocampal mossy fiber system. Brain Res. Rev. 11, 335357.

21. Gahwiler B. H. (1998) Organotypic cultures of neural tissue. Trends Neurosci. 11, 484-489. 
22. Gandy S., Stafstrom C., Turner B., Sweeney D., Breslow J., Greengard P., Smith J. and Quimet C. (1995) Aged apoE-deficient mice: abnormal learning and glial markers but no obvious neuropathology. Soc. Neurosci. Abstr. $21,5$.

23. Geddes J. W., Monaghan D. T., Cotman C. W., Lott I. T., Kim R. C. and Chui H. C. (1985) Plasticity of hippocampal circuitry in Alzheimer's disease. Science 230, 1179-1181.

24. Gordon I., Genis I., Grauer E., Sehayek E. and Michaelson D. M. (1996) Biochemical and cognitive studies of apolipoproteinE-deficient mice. Molec. Chem. Neuropath. 28, 97-103.

25. Harris-White M. E., Frautschy S. A. and Cole G. M. (1998) Methods for evaluating a slice culture model of Alzheimer's disease. In Methods in Brain Aging (eds Timiras P. and Sternberg H.), pp. 55-65, Springer-Verlag, Berlin.

26. Heinonen O., Soininen H., Sorvari H., Kosunen O., Paljarvi L., Koivisto E. and Riekkinen P. J. (1995) Loss of synaptophysinlike immunoreactivity in the hippocampal formation is an early phenomenon in Alzheimer's disease. Neuroscience 64, (2) 375-384.

27. Henderson V. W. (1997) The epidemiology of estrogen replacement therapy and Alzheimer's disease. Neurology 45, (Suppl 7) $\mathrm{S} 27-\mathrm{S} 35$.

28. Hyman B. T., van Hoesen G. W., Damasio A. R. and Barnes C. L. (1984) Alzheimer's disease: cell-specific pathology isolates the hippocampal formation. Science 225, 1168-1170.

29. Igbavboa U., Avdulov N. A., Chochina S. V. and Wood W. G. (1997) Transbilayer distribution of cholesterol is modified in brain synaptic plasma membraines of knockout mice deficient in the low-density lipoprotein receptor, apolipoprotein E, or both proteins. J. Neurochem. 69, 1661-1667.

30. Igbavboa U., Avdulov N. A., Schroeder F. and Wood W. G. (1996) Increasing age alters transbilayer fluidity and cholesterol asymmetry in synaptic plasma membranes of mice. J. Neurochem. 66, 1717-1725.

31. Krzywkowski P., Gagne J., Chabot C., Momoli F., Rochford J., Massicotte G. and Poirier J. (1997) Pharmacology of the cholinergic and glutamatergic systems in behaviorally impaired ApoE knockout mice. Soc. Neurosci. Abstr. $23,1895$.

32. Laskowitz D. T., Sheng H., Bart R., Joyner K. A., Roses A. D. and Warner D. S. (1997) Apolipoprotein E-deficient mice have increased susceptibility to focal ischemia. J. cerebr. Blood Flow Metab 17, 753-758.

33. LeBlanc A. C. and Poduslo J. F. (1990) Regulation of apolipoprotein E gene expression after injury of the rat. J. Neurosci. Res. 25, 162-171.

34. Loy R., Lynch G. and Cotman C. W. (1977) Development of afferent lamination in the fascia dentata of the rat. Brain Res. 121, 229-243.

35. Lubbers K. and Frotscher M. (1988) Differentiation of granule cells in relation to GABAergic neurons in the rat fascia dentata: combined Golgi/EM and immunocytochemical studies. Anat. Embryol. 178, 119-127.

36. Mahley R. W. (1988) Apolipoprotein E: cholesterol transport protein with expanding role in cell biology. Science 240, 522 630.

37. Masliah E., Mallory M., Ge N., Alford M., Veinbergs I. and Dorsesd A. (1995) Neurodegeneration in the central nervous system of apoE-deficient mice. Expl Neurol. 136, 107-122.

38. Masliah E., Mallory M., Alford M., Ge N. and Mucke L. (1995) Abnormal synaptic regeneration in hAPP695 transgenic and ApoE knockout mice. In Research Advances in Alzheimer's Disease and Related Disorders (eds Iqbal K., Mortimer J., Winblad B. and Wisniewski H. M.), pp. 405-414. Wiley, Chichester.

39. Masliah E., Mallory M., Hansen L., Alford M., Albright T. and DeTeresa R. (1991) Patterns of aberrant sprouting in Alzheimer disease. Neuron 6, 729-739.

40. Masliah E., Mallory M., Veinbergs I., Miller A. and Samuel W. (1996) Alterations in apolipoprotein E expression during aging and neurodegeneration. Prog. Neurobiol. 50, 493-503.

41. Masliah E., Samuel W., Veinbergs I., Mallory M., Mante M. and Saitoh T. (1998) Neurodegeneration and cognitive impairment in apoE-deficient mice is ameliorated by infusion of recombinant ApoE. Brain Res. 751, 307-314.

42. McKee A. C., Kosik K. S. and Kowall N. W. (1991) Neuritic pathology and dementia in Alzheimer's disease. Ann. Neurol. 30, 156-165.

43. Morse J. K., Dekosky S. T. and Scheff S. (1992) Neurotrophic effects of steroids on lesion-induced growth in the hippocampus. Expl Neurol. 118, 47-52.

44. Mouchel Y., Lefrancois T., Fages C. and Tardy M. (1995) Apolipoprotein E gene expression in astrocyes: developmental pattern and regulation. NeuroReport 7, 205-208.

45. Muller D., Buchs P. A. and Stoppini L. (1993) Time course of synaptic development in hippocampal organotypic cultures. Devl Brain Res. 71, 93-100.

46. Muller H. W., Gebicke-Harter P. J., Hangen D. H. and Shooter E. M. (1997) A specific 37,000-Dalton protein that accumulates in regenerating but not in nongenerating mammalian nerves. Science 228, 499-501.

47. Nakai M., Kawamata T., Taniguchi T., Maeda K. and Tanaka C. (1996) Expression of apolipoprotein E mRNA in rat microglia. Neurosci. Lett. 211, 41-44.

48. Narita M., Bu G., Holtzman D. M. and Schwartz A. L. (1997) The low-density lipoprotein receptor-related protein, a multifunctional apolipoprotein E receptor, modulates hippocampal neurite development. J. Neurochem. 68, 587-595.

49. Paganini-Hill A. (1996) Estrogen replacement therapy and Alzheimer's disease. Br. J. Obstet. Gynaecol. 103, (13) 80-86.

50. Piedrahita J. A., Zhang S. H., Hagaman J. R., Oliver P. M. and Maeda N. (1992) Generation of mice carrying a mutant apolipoprotein E gene inactivated by gene targeting in embryonic stem cells. Proc. natn. Acad. Sci. U.S.A. 89, 44714475.

51. Pitas R. E., Boyles J. K., Lee S. H., Foss D. and Mahley R. W. (1987) Astrocytes synthesize apolipoprotein E and metabolize apolipoprotein E-containing lipoproteins. Biochem. biophys. Res. Commun. 917, 148-161.

52. Poirier J. (1994) Apolipoprotein E in animal models of CNS injury and in Alzheimer's disease. Trends Neurosci. 17, 525 530.

53. Poirier J., Baccichet D. D. and Gauthier S. (1993) Cholesterol synthesis and lipoprotein reuptake during synaptic remodeling in hippocampus in adult rats. Neuroscience 55, 81-90.

54. Poirier J., Hess M., May P. C. and Finch C. E. (1991) Cloning of hippocampal Poly(A) RNA sequences that increase after entorhinal cortex lesion in adult rat. Molec. Brain Res. 9, 191-195.

55. Popko B., Goodrum J. F., Bouldin T. W., Zhang S. H. and Maeda N. (1993) Nerve regeneration occurs in the absence of apolipoprotein E in mice. J. Neurochem. 60, 1155-1158.

56. Puttfarcken P. S., Manelli A. M., Falduto M. T., Getz G. S. and LaDu M.-J. (1997) Effect of apolipoprotein E on neurite outgrowth and b-amyloid-induced toxicity in developing rat primary hippocampal cultures. J. Neurochem. 68, 760-769. 
57. Ribak C. E. and Navetta M. S. (1994) An immature mossy fiber innervation of hilar neurons may explain their resistance to kainate-induced cell death in 15-day-old rats. Devl Brain Res. 79, 47-62.

58. Roses A. D. and Saunders A. M. (1997) ApoE, Alzheimer's disease, and recovery from brain stress. Ann. N. Y. Acad. Sci. 826, 200-212.

59. Saada A., Dunaevsky-Hutt A., Aamar A., Reichert F. and Rotshenker S. (1995) Fibroblasts that reside in mouse and frog injured peripheral nerves produce apolipoproteins. J. Neurochem. 64, 1996-2003.

60. Samuel W., Masliah E., Hill L. R., Butters N. and Terry R. (1994) Hippocampal connectivity and Alzheimer's dementia: effects of synapse loss and tangle frequency in a two-component model. Neurology 44, 2081-2088.

61. Scheff S. W. (1989) Synaptic reorganization after injury: the hippocampus as a model system. In Neural Regeneration and Transplantation, pp. 137-156. Alan R. Liss, Inc., New York.

62. Scheff S. W., Benardo L. S. and Cotman C. W. (1980) Decline of reactive fiber growth in the dentate gyrus of aged rats compared to young adult rats following entorhinal cortex removal. Brain Res. 199, 21-38.

63. Sekiguchi M., Abe H., Nagato Y., Tanaka O., Guo H. and Nowakowski R. S. (1996) The abnormal distribution of mossy fiber bundles and morphological abnormalities in hippocampal formation of dreher-J (dr-J/dr-J) mouse. Devl Brain Res. 92, $31-$ 38 .

64. Sherwin B. B. (1997) Estrogen effects on cognition in menopausal women. Neurology 48, (Suppl. 7) S21-S26.

65. Slomianka L. and Geneser F. A. (1997) Postnatal development of zinc-containing cells and neuropil in the hippocampal region of the mouse. Hippocampus 7, (3) 321-340.

66. Sparks D. L., Liu H., Gross D. R. and Scheff S. W. (1995) Increased density of cortical apolipoprotein E immunoreactive neurons in rabbit brain after dietary administration of cholesterol. Neurosci. Lett. 187, $142-144$.

67. Srivastava R.-A. K. (1996) Regulation of the apolipoprotein E by dietary lipids occurs by transcriptional and post-transcription mechanisms. Molec. cell. Biochem. 155, 153-162.

68. Srivastava R. A., Bhasin N. and Srivastava N. (1998) Apolipoprotein E gene expression in various tissues of mouse and regulation by estrogen. Biochem. molec. Biol. Int. 38, 91-101.

69. Stanfield B. B. and Cowan W. M. (1997) The development of the hippocampal region. In Cerebral Cortex (eds Peters A. and Jones E. G.), Vol. 7, Development and Maturation of the Cerebral Cortex, pp. 91-122. Plenum, New York

70. Stone D. J., Rozovsky I., Morgan T. E., Anderson C. P. and Finch C. E. (1998) Increased synaptic sprouting in response to estrogen via an ApoE-dependent mechanism: implication for Alzheimer's disease. J. Neurosci. 18, 3180-3185.

71. Stone D. J., Rozovsky I., Morgan T. E., Anderson C. P., Hajian H. and Finch C. E. (1997) Astrocytes and microglia respond to estrogen with increased apoE mRNA in vivo and in vitro. Expl Neurol. 143, 313-318.

72. Stoppini L., Buchs P.-A. and Muller D. (1993) Lesion-induced neurite sprouting and synapse formation in hippocampal organotypic cultures. Neuroscience 57, 985-994.

73. Stoppini L., Buchs P. A. and Muller D. (1991) A simple method for organotypic cultures of nervous tissue. J. Neurosci. Meth. 37, 173-182.

73a. Sun Y., Wu S., Bu G., Onifade M. K., Patel S. N., LaDu M. J., Fagan A. M. and Holtzman D. M. (1998) Glial fibrillary acidic protein-apolipoprotein $\mathrm{E}$ (apoE) transgenic mice: astrocyte-specific expression and differing biological effects of astrocytesecreted apoE3 and apoE4 lipoproteins. J. Neurosci. 18, 3261-3272.

74. Sutula T., Cascino G., Cavazos J., Parada I. and Ramires L. (1989) Mossy fiber synaptic reorganization in the epileptic human temporal lobe. Ann. Neurol. 26, 321-330.

74a. Tang M. X., Jacobs D., Stern Y., Marder K., Schofield P., Gurland B., Andrews H. and Mayeux R. (1996) Effect of oestrogen during menopause on risk and age at onset of Alzheimer's disease. Lancet 348, 429-432.

75. Teter B., Soorya N., Beech W., Harris-White M. E., Frautschy S. A. and Cole G. M. (1997) Estrogen regulation of apolipoprotein E in microglia and in relation to neuronal sprouting. Soc. Neurosci. Abstr. 23, 1653.

76. Toran-Allerand C. D. (1998) The estrogen/neurotrophin connection during neural development: is co-localization of estrogen receptors with the neurotrophins and their receptors biologically relevant?. Devl Neurosci. 18, 36-48.

77. Veinbergs I., Jung M. W., Young S. J., Van Uden E. , Groves P. M. and Masliah E. (1998) Altered long-term potentiation in the hippocampus of apolipoproteinE-deficient mice. Neurosci. Lett. 249, 71-74.

78. Weisgraber K. H., Roses A. D. and Strittmatter W. J. (1994) The role of apolipoprotein E in the nervous system. Curr. Opin. Lipid. 5, 110-116.

79. Wong M. and Moss R. L. (1992) Long-term and short-term electrophysiological effects of estrogen on the synaptic properties of hippocampal CA1 neurons. J. Neurosci. 12, (8) 3217-3225.

80. Woolley C. S. and McEwen B. S. (1993) Roles of estradiol and progesterone in regulation of hippocampal dendritic spine density during the estrous cycle in the rat. J. comp. Neurol. 336, 293-306.

81. Zimmer J. and Gahwiler B. H. (1987) Growth of hippocampal mossy fibers: a lesion and coculture study of organotypic slice cultures. J. comp. Neurol. 264, 1-13.

\section{(Accepted 13 October 1998)}

Note added in proof-The difference in regional sensitivity of granule cells to estrogen-stimulated neurotrophic effects has also been observed in adult, female rats, where short-term estrogen replacement in long-term estrogen-derived females increases dentate granule cell spine density primarily by the dorsal region. [G. Einstein, personal communication; Miranda P., Williams C. L., and Einstein G. Granule cells are sexually dimorphic in their response to estradiol (submitted)]. 